\title{
MONTAGEM DE UM PROTÓTIPO DE VÁLVULA AUTOMATIZADA DE BAIXO CUSTO
}

\author{
D. M. MORAES ${ }^{1,}$ D. C. SILVA ${ }^{2}$ e F. A. C. FLOREZ ${ }^{1}$ \\ ${ }^{1}$ Universidade Federal do Maranhão, Centro de Ciências Exatas e suas Tecnologias, \\ Departamento de Engenharia Química \\ E-mail para contato: dyogo_111@ @otmail.com
}

RESUMO - Com o intuito de conseguir equipamentos mais baratos e eficientes, a utilização de materiais de baixo custo vem se tornando uma boa opção nos últimos anos pela sua viabilidade e fácil implementação. O método apresenta uma válvula de PVC, onde foi criada uma caixa de proteção que serve como suporte para o acoplamento de um motor, onde é ligado ao eixo central da válvula para transmitir o movimento do eixo do motor fazendo com que ela abra e feche. Na caixa de proteção também foi acoplado dois LDR's que são utilizados como sensores de parada (aberto ou fechado) esses serão acionados por um LED que está acoplado a caixa onde passa o eixo que faz ligação motor-válvula. O motor é controlado por uma ponte-h que estará dando o direcionamento do movimento do eixo do motor (horário ou anti-horário), a ponte-h e os dois LDR’s são ligados ao arduino onde, controlará todo o sistema.

\section{INTRODUÇÃO}

Experiências têm mostrado que a hidráulica vem se destacando e ganhando espaço como um meio de transmissão de energia nos mais variados segmentos do mercado, sendo a Hidráulica Industrial e Mobil as que apresentam um maior crescimento. Porém, pode-se notar que a hidráulica está presente em todos os setores industriais. Amplas áreas de automatização foram possíveis com a introdução de sistemas hidráulicos para controle de movimentos. (PARKER.2001)

Aproximadamente 5\% dos custos totais de uma indústria de processo químico se referem à compra de válvulas. Em termos de número de unidades, as válvulas perdem apenas para as conexões de tubulação. É um mercado estável de aproximadamente US\$ 2 bilhões por ano. (RIBEIRO.1999)

A utilização de métodos automáticos é muito importante para as indústrias sejam elas de grande médio ou pequeno porte que querem manter suas operações em pleno funcionamento, a automação traz grandes benefícios como maior segurança e produtividade e menor intervenção humana em áreas que poderiam ser fatais ao ser humano intervir.

Neste artigo será descrita a montagem de um protótipo de válvula automatizada utilizando linguagem $\mathrm{C}++$ e controlador arduino com o objetivo de conseguir baixo custo e uma performance de excelência, foi utilizada uma válvula de PVC e LDR's pelo seu baixo custo e 
facilidade de manuseio pode-se observar a grande aplicabilidade e facilidade de implementação desse método o mesmo pode ser conectado a um sistema de controle.

\section{MATERIAL}

\subsection{Arduino}

O controlado escolhido foi o arduino MEGA328P (Fig.1 - c ) por ter um código aberto e fácil programação além de ser um controlador de fácil implementação qualquer pessoa que não tem muito conhecimento em eletrônica e programação pode aprender a programar arduino pelo vasto conteúdo que está disponível na internet o número de comunidades e o espirito de cooperativismo das pessoas que trabalham na área facilita o aprendizado do mesmo fazendo com que ele se torne uma ferramenta muito eficaz no controle de processos.

Segundo McRoberts (2012) desde que o Arduino Project teve início em 2005, mais de 150.000 placas Arduino foram vendidas em todo o mundo. O número de placas-clone não oficiais sem dúvida supera o de placas oficiais, assim, é provável que mais de 500 mil placas Arduino e suas variantes tenham sido vendidas. Sua popularidade não para de crescer, e cada vez mais pessoas percebem o incrível potencial desse maravilhoso projeto de fonte aberta para criar projetos interessantes rápida e facilmente, com uma curva de aprendizagem relativamente pequena.

O Arduino pode ser utilizado para desenvolver objetos interativos independentes, ou pode ser conectado a um computador, a uma rede, ou até mesmo à Internet para fazer determinadas funções programadas.

\subsection{LDR}

O fotorresistor ou LDR (Fig.1 - a) (Light Dependent Resistor) e um componente construído de material semicondutor (sulfeto de cadmio) cuja resistência elétrica diminui quando aumenta a incidência de radiação luminosa. Existem em diversos tamanhos e potência. São usados em detecção de fumaça, alarmes de segurança e roubo, controle de luminosidade, contagem de peças e etc.... (SEBRA.2010)

\subsection{Ponte-H}

Ponte-H (Fig.1 - d) é um circuito electrónico que permite variar velocidades de um motor DC, assim como comutar o sentido de rotação dos motores, através de um sinal PWM. Estes circuitos são muito utilizados em robótica e estão disponíveis em circuitos prontos ou podem ser construídos por componentes.

Para o projeto foi utilizado um circuito encontrado no site ROBOTIZANDO que forneceu o circuito gratuitamente, e pode ser utilizado para ser aplicações em cadeiras de roda a cadeirantes. O circuito a seguir foi montado no LIAP-UFMA (Laboratório de instrumentação e Automação de Processos). 


\subsection{LED}

O diodo emissor de luz (Fig.1 - b) e basicamente uma juncão PN na qual existe uma abertura pela qual sai radiação luminosa quando a junção e polarizada diretamente. Quando polarizado reversamente, tem o mesmo comportamento de urn diodo comum. A cor da radiação pode ser verde, amarela, vermelha, azul ou mesmo infravermelha, depende dos materiais usados para construir 0 LED. Quando polarizado diretamente, a queda de tensão pode variar de $1 \mathrm{~V}$ a $2 \mathrm{~V}$, dependendo da corrente. Em geral, uma corrente de $20 \mathrm{~mA}$ e suficiente para uma boa luminosidade. A máxima tensão reversa costuma ser menor do que 10V. (SEBRA.2010)

Figura 1 - (a) LDR; (b) LED; (c) Arduino as partes e a pinagem e (d) Circuito Ponte - H.

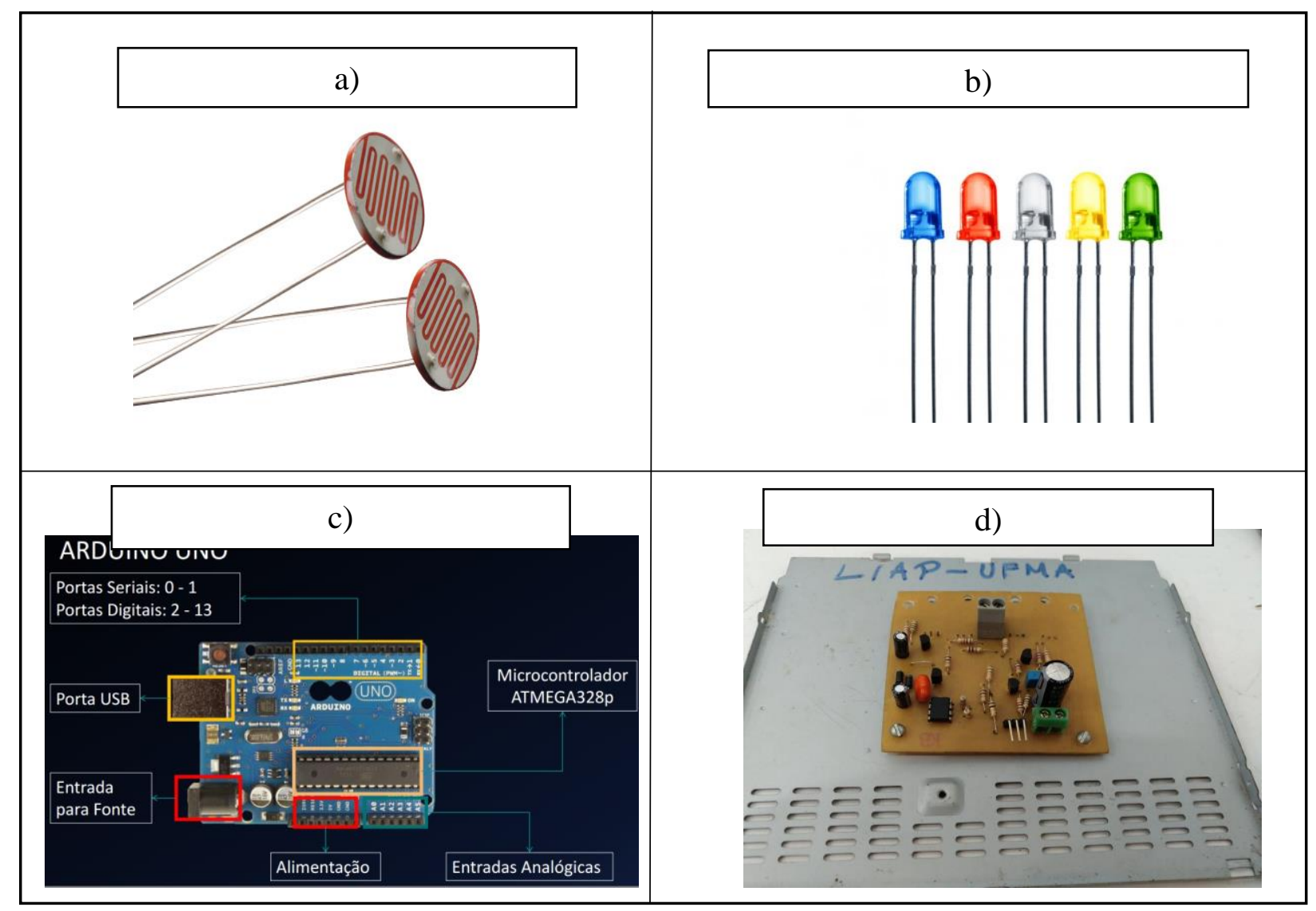

\subsection{Registro de Esfera}

As válvulas são dispositivos importantes para a instalação de água da sua residência, comércio ou indústria. Com seu sistema abre e fecha, controla-se e monitora-se o fluxo e a pressão de um sistema. Pode ser utilizada em diferentes aplicações, desde os complexos sistemas de irrigação e construção naval, até as instalações de máquina de lavar roupa e piscinas. Fabricadas em PVC, são resistentes. O registro de esfera (Fig.2 - a) é responsável pelo bloqueio ou liberação do fluxo de água para os outros pontos de distribuição da sua 
residência, comércio ou indústria. Sendo necessário realizar uma manutenção, com apenas 1/4 de volta interrompe-se a entrada da água (Tigre, 2016).

\subsection{Motor com prato de redução}

Uma máquina elétrica (Fig.2 - b) é uma máquina capaz de converter energia mecânica em energia elétrica (gerador) ou energia elétrica em mecânica (motor). Quando se trata de um gerador, a rotação é suprida por uma fonte de energia mecânica como, por exemplo, uma queda d'água, para produzir o movimento relativo entre os condutores elétricos e o campo magnético e gerar, desse modo, uma tensão entre os terminais do condutor. No caso de motores, o funcionamento é inverso: energia elétrica é fornecida aos condutores e ao campo magnético (no caso de ele ser gerado por eletroímãs) para que surja a força magnética nos condutores, compondo um binário e causando a rotação (energia mecânica). Concluindo, sempre há movimento relativo entre condutor e campo magnético.

O prato de redução (Fig.2 - c) é um conjunto de engrenagem para reduzir a velocidade do motor fazendo com que motores de altas rotações possam ser utilizados em equipamentos que necessitem de uma menor rotação

Figura 2 - (a) Válvula (Registro), (b) Motor e (c) Prato de Redução.

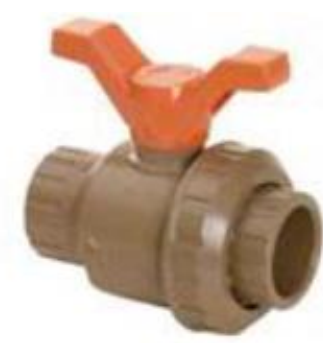

(a)

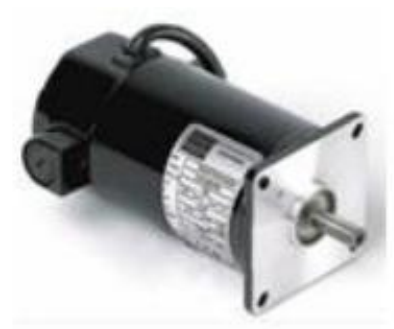

(b)

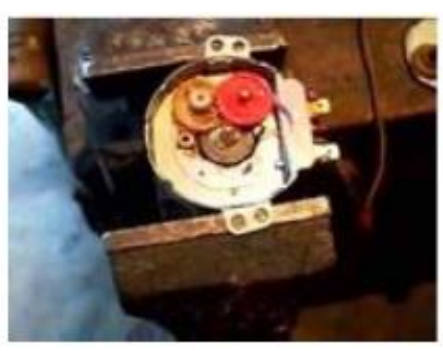

(c)

\section{Montagem e funcionamento}

Iniciou se a construção da caixa (Fig.3 - a) de suporte onde foi colocado a válvula a construção foi bem simples uma caixa de madeira com os furos dimensionados para receber o motor e a válvula assim inicia - se a construção do eixo (Fig.3 - b) que transmite a movimentação do motor para a válvula para isso foi retirado o volante da válvula e o eixo construído foi acoplado diretamente na haste da válvula. No eixo foi feito um furo que se encaixava corretamente com a forma da haste da válvula e o outra lado foi feito um furo de $8 \mathrm{~mm}$ que é o diâmetro do eixo do motor e transversalmente foi colocado um parafuso para que o eixo não escapasse do movimento ou desgastasse o eixo com a parte física do sistema montada neste também foi colocado um disco de $2 \mathrm{~mm}$ de espessura com divisões de $1^{\circ}$ grau cada divisão possuía um furo de $1 \mathrm{~mm}$ para passagem de luz com o sistema físico montado iniciou se a montagem da parte eletrônica. 
Figura 3 - (a) Vista da caixa de suporte desmontada (b) Eixo acoplado no motor

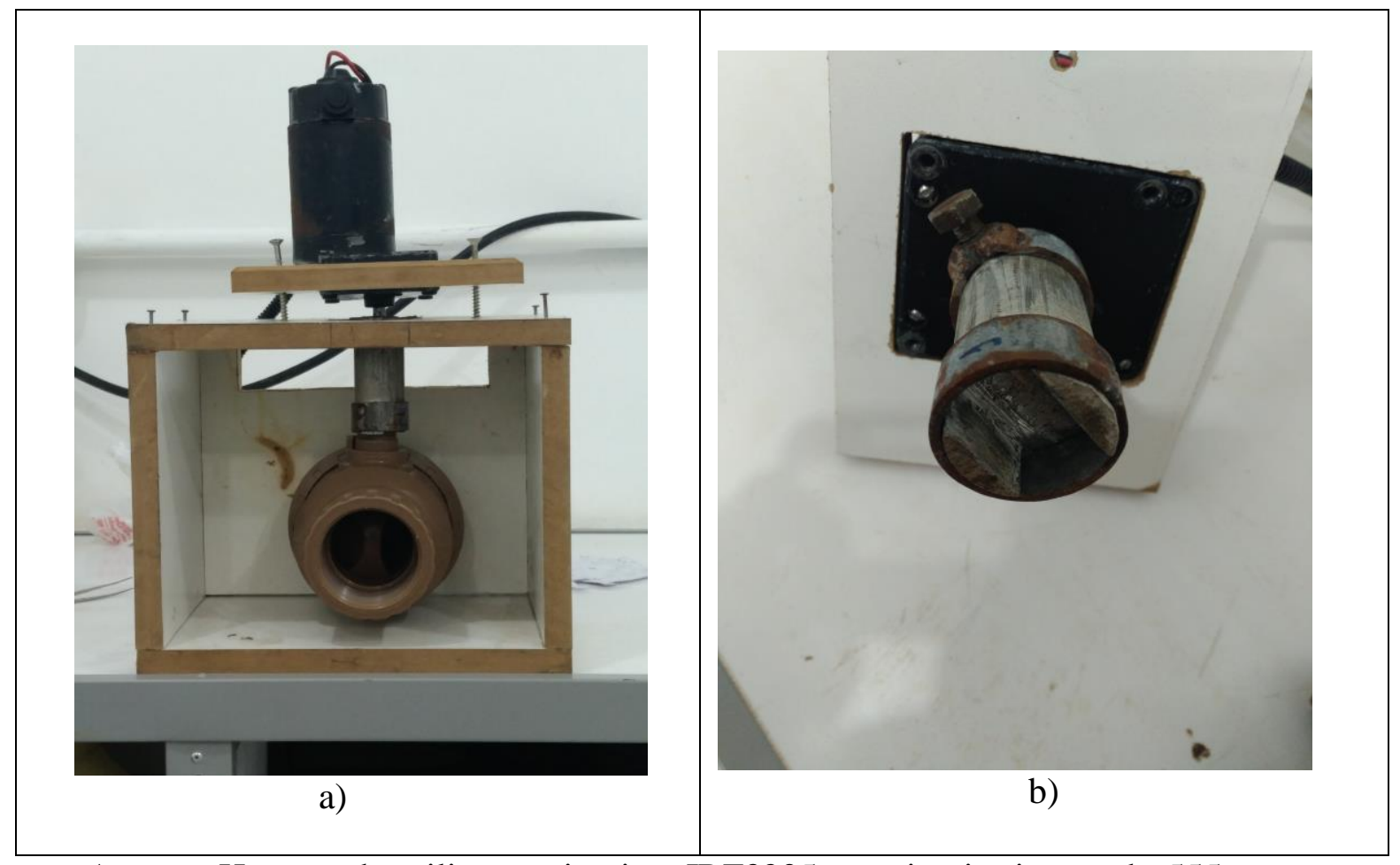

A ponte-H montada utiliza os circuitos IRF3205 e o circuito integrado 555 esses são os principais componentes desse sistema o sistema montado com o circuito 555 tem como finalidade dobrar a tensão (Fig. 3 - c) inserida na ponte como estamos trabalhando com 12v a tensão de saída do circuito é 24v essa tensão ira alimentar os IRF3205 (Fig.3 - d) que fazem com que o movimento de rotação seja horário ou anti-horário esse sistema será controlado pelo arduino que por sua está ligado a um encoder rotativo na parte interna da caixa próximo ao disco foi colocado na parede da caixa um LED e um LDR o disco ficara entre esses dois para que quando o disco se movimentar e houver a passagem do furo a luz passe e o LDR diminua a resistência assim conte um pulso.

Figura 3 - (c) esquema do circuito dobrador de tensão (d) esquema do circuito com IRF3205

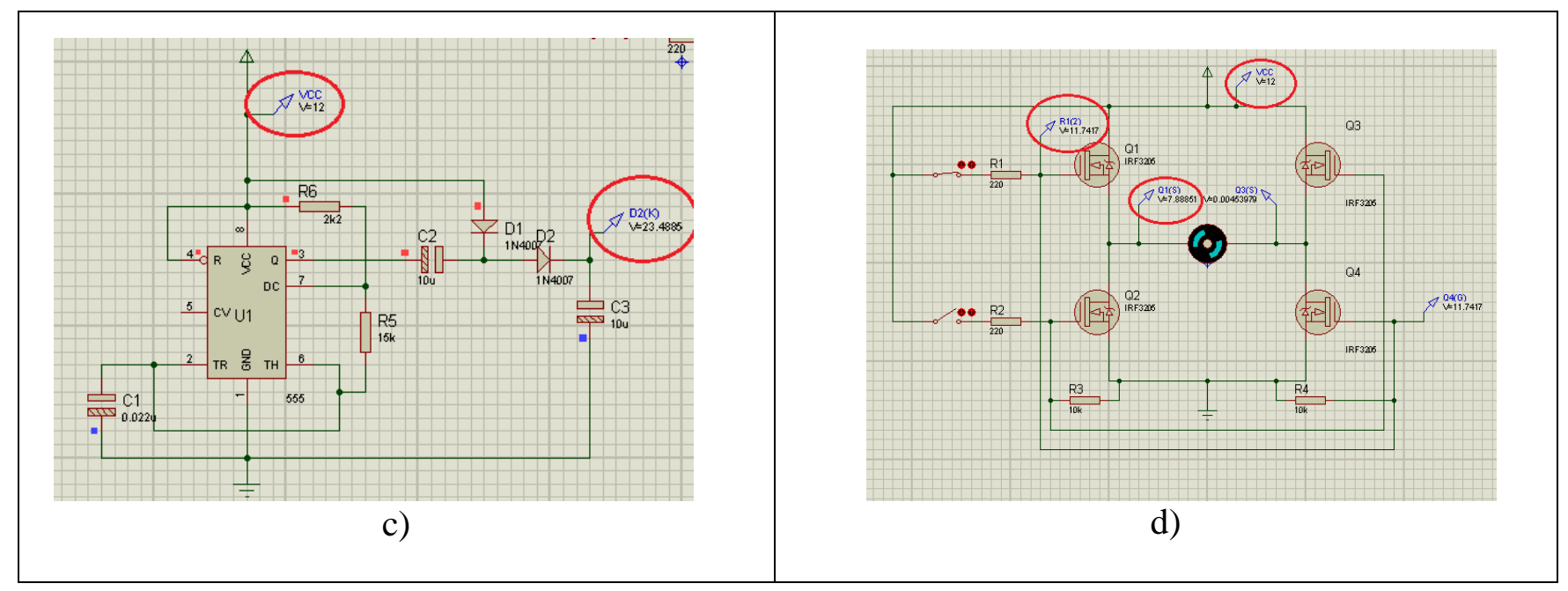


O funcionamento completo de todo sistema pronto feito da seguinte forma é girado o enconder rotativo um certo número de vezes assim esse dado é armazenado no arduino que ativa uma saída dependendo do sentido da rotação a ponte $h$ fara sua função que é ligar o motor conforme o motor é ligado o disco se movimentara junto com o eixo o sistema que está acoplado a parede da caixa vai contar até que se iguale o número de rotações do encoder rotativo com o número de vezes que o LDR recebeu luz assim o sistema para então pode se conseguir uma abertura de grau em grau com relação a esfera da válvula. O botão interno do encoder rotativo serve para abertura rápida ele faz o caminho completo ele vai de 0 a $90^{\circ}$ (abertura máxima) com um toque

\section{CONCLUSÃO}

O experimento obteve êxito, o mecanismo se comportou como esperado a válvula abre e fecha com precisão de um grau assim pode se obter uma grande variação de vazões podendo fazer um controle mais preciso de sistemas industriais já que se pode obter variações bem pequenas. A proposta de se usar o arduino para este tipo de protótipo se mostrou como uma alternativa viável por permitir a fácil implementação o que o torna um equipamento promissor em industrias e até mesmo residencial. Desta forma, podemos concluir que a válvula produzida pode ser utilizada como uma ferramenta importante para garantir o controle de processos industriais garantindo uma melhor eficiência no processo.

\section{REFERÊNCIAS}

ALBUQUERQUE, R. O.; SEABRA A.C. Utilizando Eletrônica. 2. ed. São Paulo: Erica, 2010.

BASCONCELLO D.O. Ponte-H 12V 40ª Disponível em:

http://www.robotizando.com.br/artigo_ponte_h_pg1.php . Acessado em:02/01/2017

BOJORGE, N. Válvulas de Controle, 2014. Disponível em:

http://www.professores.uff.br/controledeprocessos-

eq/images/stories/Aula09_Instrumen_Valvulas_2sem2014_parte1.pdf Acesso em: 20/03/2017.

BOYLESTAD, R. L.; NASHELSKY, L. Dispositivos Eletrônicos e Teoria de Circuitos. 11. ed. Pearson.

GOMES; M. R. Apostila de hidráulica. CEFET/Ba 2008 Unidade Santo Amaro. Disponível em http://campusvirtual.edu.uy/archivos/mecanicageneral/CURSO\%20BINACIONAL\%20URUGUAY-BRASIL\%202011/PLC/apostilacompleta.pdf. Acesso 20/03/2017

MCROBERTS, M. Arduino Básico. 01. ed. São Paulo: Novatec, 1998.

RIBEIRO.M.A Válvulas de Controle e Segurança. 5. ed. Salvador-BA. Primavera 1999.

TIGRE. Registro esfera. Disponível. http://www.tigre.com.br/registros/registros-de-esfera. Acesso em: 29/03/2017. 